A wine of good taste

Can you detect the tannins in your tempranillo?

Perhaps you know your burgundy from your Beaujolais

and order 'a nice Cab Sav' when out for dinner.

Or maybe even, like the wine worshippers in the film

Sideways, you consider 'merlot' to be a swear word.

Kate Maynard turns wine buff for the benefit of \section{Vital readers.}

$\int$ $\mathrm{f}$ you answered 'yes' to the questions above, then chances are you know a lot more about wine than I do. After being reprimanded for choosing the Thai house red when eating in a Thai restaurant recently, a friend of mine decided to educate me with a trip to a wine fair. Held on a glorious early autumn day at the pavilion at Lord's Cricket Ground, sampling wines from around the world seemed an ideal way to spend a Sunday afternoon.

Upon arrival we were given our very own sampling glass to keep, and a booklet with details of each wine: origin, year and price, and a little space to make notes or mark for later purchase. Although this wine fair was held by a popular supermarket chain, no-one could complain at the range of wines represented. Spanish, Chilean, French, Australian; household names, newcomers and vintages side by side ... and we didn't hurry past the champagne stand.

Each stand held a basket of crackers, water to rinse your glass, and a bin of sand to catch the drops. Eager sales people distributed the goods to us and to our fellow tasters - who were as varied in appearance as the wines themselves. No Jilly Gooldens were evident, but neither was there anyone who seemed to have accidentally included the venue on a pub crawl. The only place where there was any light jostling was on the complementary cheese and chutney stand which, despite this, made a welcome break from the circuit.

Although an enjoyable experience, I came away from the wine fair none the wiser as to what 'legs' and 'tannins' are, and how long I really should be sticking my nose into the glass. So I have since endeavoured to find out.

\section{Approaching a wine}

\section{Colour}

Fill a clear wine glass less than halfway, to avoid splashing. Hold the glass of wine against a plain background to look at the colour. The colour is linked both to the age of the wine and also the grapes that have been used. Many young red wines are dark and dense, whereas one that has aged some years will fade to a lighter reddish brown. White wine, however, lightens from a yellow shade to a rich gold over time. Wines from cool and warm climates also vary; recognising this will come with experience.

\section{Legs}

These are the streaks of wine which form on the side of a wine glass when the liquid is swirled around. Some wine experts believe that the thicker the legs, the higher the quality of the wine, and the more watery the legs, the weaker it is.

Swirl your wine around in the glass regardless, as this will let the liquid breathe and release the aromas.

\section{Smell}

Many believe that the scent of a wine can tell you more about it than the actual taste, so don't be afraid to put your nose right in the glass and inhale. You will find that many young wines smell distinctly of fruit, but more vintage tipples may have a more full-bodied, aroma.

\section{Taste}

Surely the best bit! Take a reasonable draught, let the liquid roll about your tongue and consider drawing air through the wine while you think about the flavours and sensations. Tannic wine, by the way, is the dusty, dry feeling of a wine in your mouth. Make a mental note of what each wine tastes and smells like to compare it to others and recognise it in the future. As you become more experienced this will improve your ability to identify grape, origin, age and quality. Even Jilly and $\mathrm{Oz}$ had to start somewhere!

As hobbies go, learning more about wine can only improve your enjoyment of it, whether in complement to a meal or just when out with friends. The choice of wine available today has never been better, and wine holidays, fairs or even an afternoon at the Vinopolis in London are extremely popular. What's in your glass?

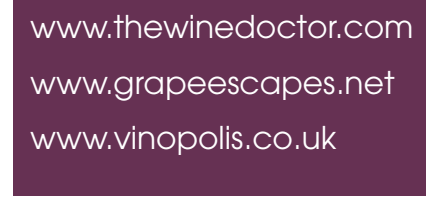

